\title{
Working for Less: Income Inequality and the Diminishing Share of Labor in China's National Wealth
}

\author{
Songtao Wang ${ }^{1}$, Tristan Kenderdine ${ }^{2} \&$ Zhen $\mathrm{Qi}^{1}$ \\ ${ }^{1}$ Shantou University Business School, Shantou, China \\ ${ }^{2}$ Australian National University Crawford School of Public Policy, Australia \\ Correspondence: Zhen Qi, Shantou University Business School, 243 Da Xue Road, Shantou, Guangdong, China. \\ Tel: 86-136-9203-7156. E-mail: Zhenqi@stu.edu.cn
}

Received: March 17, 2017

Accepted: April 12, 2017

Online Published: May 31, 2017

doi:10.5539/ass.v13n6p81

URL: https://doi.org/10.5539/ass.v13n6p81

\begin{abstract}
This paper demystifies variation in labor's share of national labor income in China from the perspective of the income gap. We extend the gross national labor income function by introducing a Gini coefficient to support our argument that the share of gross national labor income decreases with an increasing Gini coefficient. The hypotheses are tested using provincial data from 1996 to 2010: (1) the Gini coefficient's 'inverted U' shape partially contributes to the U-shaped evolution of the labor income-share; (2) China's 15 per cent decline in the labor income share can be explained by the widening income gap during that time.
\end{abstract}

Keywords: China, Income Distribution, Income Gap, Share of Labor Income, U-shaped Curve

\section{Introduction}

Labor income is possibly the most important factor influencing workers' welfare. This is especially true for people in developing countries such as China where labor is more abundant than capital. Labor income will continue to be the main source of income in China for the foreseeable future (Li \& Yan, 2007). The decline of labor's income-share implies that workers' income growth lags macroeconomic growth, and further indicates workers' slow consumption growth as the consumption ratio also fell in our time series range (Fang, 2009; Li et al., 2009). This reduces total domestic demand and ultimately affects the sustainable development of the economy. Therefore, research on China's national labor income-share change is of great significance for improving the living standards of China's citizens, optimizing the structure of the national economy and realizing sustainable economic development.

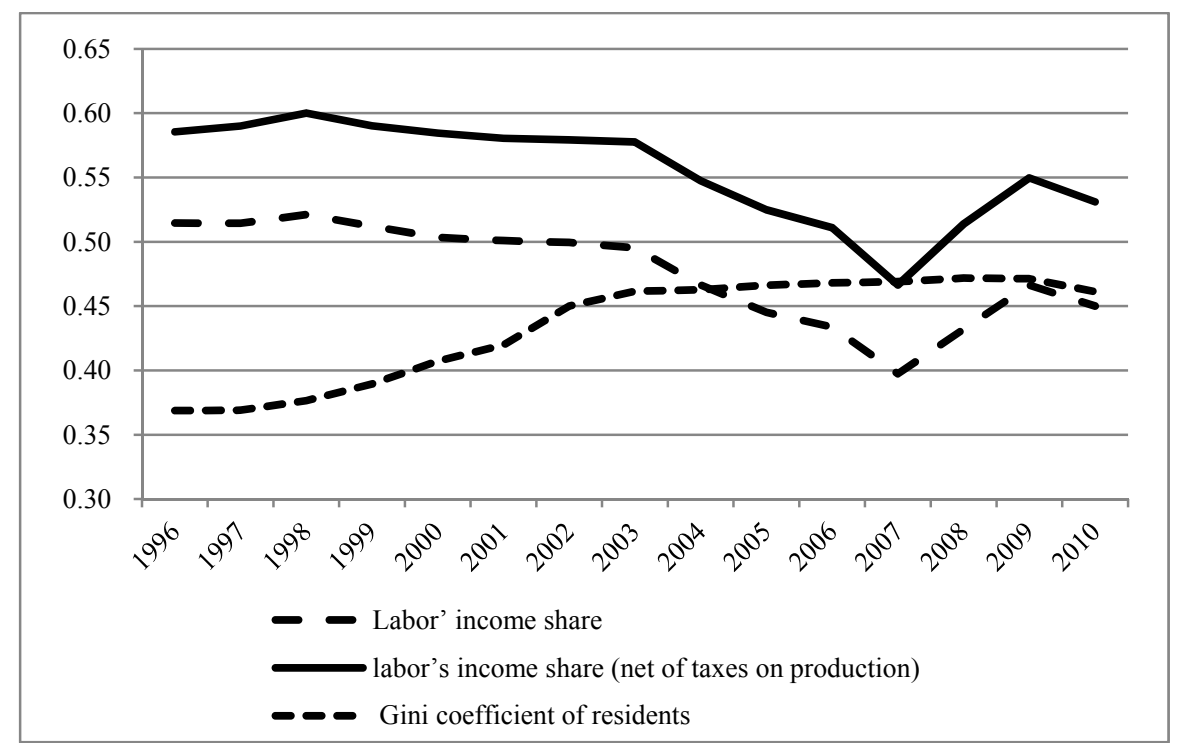

Figure 1. Labor income-share and Gini coefficient changes

Source: China statistical yearbook (1997-2011) 
Since the late 1990s, the primary distribution of national income presented a stylized characteristic that the labor income-share continuously declined until 2007. After 2008, labor's share began to gradually rise, demonstrating a U-shaped variation. According to China Statistical Yearbook GDP calculations, the share of labor income fell from $51.45 \%$ in 1996 to $39.74 \%$ in 2007 , decreasing by $11.71 \%$. The labor income-share began to rise in 2008 , with the proportion rising to $45.01 \%$ in 2010 . These changes begin to present U-shaped features, as shown in Figure 1.

Extensive research has been conducted on national labor income-share, such as Kaldor (1961), Kongsamut et al. (2001), Bentolila \& Saint-Paul (2003), Askenazy (2005), Jayadev (2007), Kabaca (2011). In recent years, research on national income labor share has attracted more interest within China. Existing research can be categorized in three areas:

First, the causes of labor's decreasing share of national income in China has been studied, such as Luo and Zhang (2009a), Bai and Qian (2009a), Liu and Wang (2009), Huang and Xu (2009), and Wei (2012) etc. The results of this research suggest the causes of the decline in labor income-share in China could be due to changes in industrial structure, technological progress, population age, and globalization.

Second, factors that influence labor share in national income have been studied, such as Luo and Zhang (2009 b), Bai and Qian (2010), Shao and Huang (2010), Fang (2011), Luo and Chen (2012), etc. However, these studies only consider factors influencing labor share such as foreign investment, ownership structure, and financing constraints.

Third, studies in the causes of U-shaped evolution trends in labor's share in national income, such as Li (2009), Gong and Yang (2010), and $\mathrm{Li}$ (2010). In these papers, the infinite labor supply in a dual economic structural transformation has been mainly used to explain the causes of labor income-share's U-shaped change.

Existing research has deepened our understanding of the decline in labor's income-share and the U-shaped characteristic. However, we still need further study because of some inadequacies in the existing research.

First, there are method faults in the previous research, such as research based on multivariate regression analysis which presents various problems, such as omitted variables, collinearity, endogenous and other robustness failings (Li, 2008).

Second, it is difficult to logically unify all existing research. For example, the study of labor share determinant factors cannot provide proper explanations for the labor share decline, and the study of labor share decline cannot explain the U-shaped characteristic.

Third, the influence of the labor share's variation on income inequality has attracted attention (Daudey \& Garcia, 2007; Li, 2009). However, these papers cannot answer questions of how income inequality affects labor income-share and how to measure this effect. In terms of the study on China, the existing literature has not calculated the contribution of related factors to China's national labor share's variation.

Different from the literature above, this paper proposes using income difference to explain the labor income-share variation. We argue that income inequality is an important influencing factor in labor's income-share variation; the increase in income inequality is a significant reason for labor income-share decline in China. The inverted U-shaped characteristic of income difference can partly explain the U-shaped characteristic of labor-income share and allow quantitative analysis on the influence of income difference variation. To the best of our knowledge, this is the first study of China's labor income-share from this perspective.

When we observe macro-data that the Gini coefficient in China shows inverted U-shaped characteristics and the inverted coupling feature is shown in labor share's U-shaped characteristic, we may find some relationship exists between them. Although the income difference itself may not influence gross labor income-share, the underlying mechanism at work relates to capital variation. Capital variation affects not only income difference but also the gross labor income-share. Therefore, the variation of income difference reflects the gross labor income-share variation. In reality, different levels of market participation (Yin \& Cai, 2001; Bai, 2004; Shi \& Ma, 2006) leads capital and labor to imperfectly circulate thus resulting in different capital intensity.

For a family or an individual, capital also cannot circulate perfectly, due to the ubiquitous financing restriction in China (Luo \& Zhang, 2012). Capital and labor structure cannot therefore reach an optimal level because capital-labor cannot flow freely. It means the marginal production efficiency of production factors varies by sector or individual and the capital stock per capita difference will cause differences in production per capita (income difference), capital income, and labor income and its share. Therefore, income difference variation affects the gross labor income and its share. 
In this paper, based on the above background and theoretical logic, we attempt to study the influence on national labor income and its share exerted by income differences both theoretically and empirically. Initially, we present the theoretical conditions to judge the condition of the influence that income difference makes on national labor income and its share, and propose the metering method to quantitatively measure the influence of Gini coefficient variation exerted on national labor income and its share.

This paper has the following contributions:

First, we offer a new perspective to understand labor income-share decline in China and its U-shaped characteristic.

Second, we point out the theoretical conditions of marginal labor income decline; and strictly demonstrate that the increasing of the Gini coefficient will reduce the national labor income and its share when marginal labor income decreases.

Third, we propose a new method to quantitatively analyze the influence of Gini coefficient variation exerted on national labor income and its share. This method is also applied to China's case.

The rest of this paper is presented in three sections. Section 2 presents the formal theoretical model and the key propositions; Section 3 shows the supporting empirical evidence; Section 4 discusses the implications of this study and concludes.

\section{Theoretical Analysis}

In this section, we first deduce the condition of decreasing marginal income through a neo-classical production model and a constant elasticity of substitution production function. Further, based on the classical Pareto function, we build a national gross labor income function with Gini coefficient, to test whether the increase of the Gini coefficient will decrease national gross labor income and its share when the marginal labor income declines gradually. Finally, we propose a new method to calculate the influence that Gini coefficient variation exerts on national labor income and its share.

a. Elasticity of capital-labor substitution and decreasing marginal labor income: micro-analysis

Set the capital stock of an economic entity $i$ as $K_{i}$, the amount of labor as $L_{i}$. The production function is $Y_{i}=F\left(K_{i}, L_{i}\right)$; we have the following assumptions for this production function: constant returns to scale, perfectly competitive market, no technology reform and second order differentiable. The per capita output is $y_{i}=Y_{i} / L_{i}$ and the capital stock per capita is $k_{i}=K_{i} / L_{i}$. Because of constant returns to scale, $Y_{i}=$ $L_{i} F\left(K_{i} / L_{i}, 1\right)=L_{i} f\left(\mathrm{k}_{\mathrm{i}}\right)$. The function $y_{i}=f\left(k_{i}\right)$ is the per capita output function.

The price-level of output can be standardized as 1 . In order to simplify analysis, let us assume the capital depreciation rates is 0 , then let the profit of a manufacturer be:

$$
F\left(K_{i}, L_{i}\right)-r_{i} K_{i}-\omega_{i} L_{i}=\left(f\left(k_{i}\right)-r_{i} k_{i}-\omega_{i}\right) L_{i}
$$

where $r_{i}$ is the rate of capital return and $\omega_{i}$ is wages (labor income).

To maximize profits, the manufacturer can make a choice on how much capital and labor they should invest for production. That is:

$$
\max _{K_{i}, L_{i}} F\left(K_{i}, L_{i}\right)-r_{i} K_{i}-\omega_{i} L_{i}
$$

Since the market is perfectly competitive, profit maximization is 0 (the per capita output is the per capita income), thus we get the optimality condition:

$$
f^{\prime}\left(k_{i}\right)=r_{i}, \omega_{i}=f\left(k_{i}\right)-k_{i} f^{\prime}\left(k_{i}\right)
$$

Since the elasticity of capital-labor substitution in Cobb-Douglas production function (C-D) is 1 , the share of labor income is calculated according to the $\mathrm{C}-\mathrm{D}$ function as a constant. The $\mathrm{C}-\mathrm{D}$ production function is therefore not suitable to study labor income share variation. We consider the constant elasticity of substitution (CES) production function:

$$
Y_{i}=F\left(K_{i}, L_{i}\right)=\mathrm{A}\left[\alpha K_{i}^{(\sigma-1) / \sigma}+(1-\alpha) L_{i}^{(\sigma-1) / \sigma}\right]^{\sigma /(\sigma-1)}
$$

Here, $\mathrm{A}>0$ and $0<\alpha<1$ is constant; $\sigma=\frac{\mathrm{d}\left(K_{i} / L_{i}\right) /\left(K_{i} / L_{i}\right)}{\mathrm{d}\left(\omega_{i} / r_{i}\right) /\left(\omega_{i} / r_{i}\right)}>0$ is the elasticity of capital stock replacement.

When $\sigma=1$ the CES production function is a C-D function.

Per capita output (income): $y_{i}=f\left(k_{i}\right)=\mathrm{A}\left[\alpha k_{i}^{(\sigma-1) / \sigma}+(1-\alpha)\right]^{\sigma /(\sigma-1)}$ 
Per capita labor income: $\omega_{i}=f\left(k_{i}\right)-k_{i} f^{\prime}\left(k_{i}\right)=(1-\alpha) \mathrm{A}\left[\alpha k_{i}{ }^{(\sigma-1) / \sigma}+(1-\alpha)\right]^{1 /(\sigma-1)}$

Labor income share: $e_{i}=\omega_{i} / y_{i}=(1-\alpha)\left[\alpha k_{i}{ }^{(\sigma-1) / \sigma}+(1-\alpha)\right]^{-1}$

It is obvious that per capita labor income and its share are both influenced by capital stock per capita (capital intensity).

We can further get: $y_{i}=f\left(k_{i}\right)=\mathrm{A}\left[\alpha k_{i}^{(\sigma-1) / \sigma}+(1-\alpha)\right]^{\sigma /(\sigma-1)}$

Set $(1-\alpha) A^{1-1 / \sigma}=b>0$, then:

$$
\omega_{i}=b y_{i}^{1 / \sigma}
$$

Set $g\left(y_{i}\right)=b y_{i}{ }^{1 / \sigma}$, and call it 'individual labor income function'. If $g^{\prime \prime}\left(y_{i}\right)<0$, marginal labor income is decreasing because $g^{\prime}\left(y_{i}\right)=(1 / \sigma) b y_{i}{ }^{1 / \sigma-1}>0$, then:

$$
\begin{gathered}
g^{\prime \prime}\left(y_{i}\right)=(1 / \sigma)(1 / \sigma-1) b y_{i}{ }^{1 / \sigma-2} \\
e_{i}=\omega_{i} / y_{i}=b y_{i} 1 / \sigma-1 \\
\partial e_{i} / \partial y_{i}=(1 / \sigma-1) b y_{i}{ }^{1 / \sigma-2}
\end{gathered}
$$

According to equation (2) we can easily get the following proposition:

Proposition 1: when the elasticity of capital-labor substitution is $\sigma>1$, it means that when capital and labor are substitutable, marginal labor income decreases. That is $g^{\prime \prime}\left(y_{i}\right)<0$

According to equation (3), we can get the following proposition:

Proposition 2: when the elasticity of capital-labor substitution is $\sigma>1$, it means that when capital and labor are substitutable, individual labor income-share proportion decreases as a function of its income, that is $\partial e_{i} / \partial y_{i}<$ 0.

Existing literature has studied Capital and labor substitution (Bentolina \& Saint-Paul, 2003). Estimation of elasticity of capital-labor substitution in China is still an open problem. Shao and Huang (2010) claim that the industrial sector elasticity of capital-labor substitution in China is less than 1. Bai and Qian (2008) argue that this value is close to 1 . Luo and Zhang (2009b) consider that it is close to but less than 1. Li (2009) argues that it is greater than 1 . The conclusions reached by these papers vary because of different estimation methods and data sources. In this paper we will use equation (1) to estimate the elasticity of capital-labor substitution.

If the capital-labor relationship is substitutable, the per-capita capital stock k will increase (for example, increase through the savings rate s), which will cause more output y and decrease labor's income share. For different economies or individuals, high capital stock always means higher per-capita output (income) and a lower share of labor income. This income difference will affect national gross labor income and its share.

b. Income difference influence on national labor income and its share: macro analysis

As is mentioned above, market segmentation in China has led to a situation where labor and capital cannot flow freely, which causes regional differences in capital stock per capita. Meanwhile wealth inequality and financing constraints lead to individual inequality in the capital stock, which then lead to regional or individual income differences. Since the levels of capital labor income and labor share are different among individuals, the income difference would influence both labor income and its share at the same time. Any change in the income difference would also lead to changes in the national labor income and its share.

Based on the classical Pareto income distribution, the Lorenz curve is established to describe a national labor income function including the Gini coefficient. We then use the function to study the influence that the Gini coefficient variation exerts on national labor income and its share.

The US statistician Lorenz described a curve, 'Lorentz curve', of a country's income distribution $L=L(p)$, which consists of the points of the accumulated population and its accumulating income share from low to high. Where $p \in[0,1]$ is population proportion and $L(p) \in[0,1]$ is the relative income proportion. Building on theLorenz curve, the Italian economist Corrado Gini defined a fair income distribution index, named the 'Gini coefficient'. It is calculated as $G=1-2 \int_{0}^{1} L(p) d p$.

Before calculating the Gini coefficient, we must understand the function of the Lorenz curve. Scholars (Ryu, et al., 1996; Sarabia, 1999; Chotikapanich et al., 2002) put forward various forms of Lorenz curve equations based on different distributions of income. Sarabia (2008) summarizes seven sorts of Gini coefficient calculation formula based on the classical income distribution of the Lorenz curve. One of the most commonly used forms is based on the Lorenz curve of classic Pareto income distribution. Its parameter estimation is highly accurate and it is widely used for practical purposes. We therefore selected aLorenz curve based on classical Pareto income 
distribution to calculate the Gini coefficient in this paper. The Lorenz curve function based on the classical Pareto income distribution is: $(p)=1-(1-p)^{B}, 0 \leq p \leq 1,0<B<1$ where $\mathrm{p}$ is population proportion accumulated by income from low to high, and $B$ is parameter. The Gini coefficient is:

So: $B=(1-G) /(1+G)$

$$
\mathrm{G}=1-2 \int_{0}^{1} L(p) d p=1-2 \int_{0}^{1}\left[1-(1-P)^{B}\right] d p=(1-B) /(1+B)
$$

we can get theLorenz curve using the Gini coefficient as the parameter:

$$
L(p)=1-(1-p)^{\frac{1-G}{1+G}}
$$

Set $Y$ as gross national income, $Y_{L}=e Y$ as national gross labor income, e as proportion of national gross labor income. Set $\mathrm{N}$ as population, so in the whole population the income of people ranked I is (Song-Tao Wan, 2011): $y_{i}=Y *\left[L\left(\frac{i}{N}\right)-L\left(\frac{i-1}{N}\right)\right]$.

Since people i's labor income function is: $\omega_{i}=g\left(y_{i}\right)$, which satisfying $0 \leq g\left(y_{i}\right) \leq y_{i}, g(0)=0, g^{\prime}\left(y_{i}\right)>0$. Then the national gross labor income is: $Y_{L}=\sum_{i=1}^{N} \omega_{i}=\sum_{i=1}^{N} g\left(y_{i}\right)=\sum_{i=1}^{i=N} g\left(Y\left[L\left(\frac{i}{N}\right)-L\left(\frac{i-1}{N}\right)\right]\right)$

Putting equation (4) to that equation, we can get:

$$
\begin{gathered}
Y_{L}=\sum_{i=1}^{N} \omega_{i}=\sum_{i=1}^{N} g\left(y_{i}\right)=\sum_{i=1}^{i=N} g\left(Y\left[L\left(\frac{i}{N}\right)-L\left(\frac{i-1}{N}\right)\right]\right) \\
e=\frac{1}{Y} \sum_{i=1}^{N} g\left(Y\left[\left(1-\frac{i-1}{N}\right)^{\frac{1-G}{1+G}}-\left(1-\frac{i}{N}\right)^{\frac{1-G}{1+G}}\right]\right)
\end{gathered}
$$

Using equation (5) and (6) we can demonstrate the following propositions:

Proposition 3: When $\mathrm{g}^{\prime \prime}(\mathrm{y})<0$, that is to say marginal labor income decreases, the national labor income and its share are both decreasing functions of the Gini coefficient $\left(\partial Y_{L} / \partial \mathrm{G}<0, \partial \mathrm{e} / \partial \mathrm{G}<0\right)$; as a result, as Gini coefficient increase, the national gross labor income and its share will decrease (and vice versa).

Demonstration: according to (5), we have:

$$
\frac{\partial Y_{L}}{\partial G}=\frac{-2 Y}{(1+G)^{2}} \sum_{i=1}^{N}\left\{g^{\prime}\left(\mathrm{y}_{\mathrm{i}}\right)\left[\left(1-\frac{i-1}{N}\right)^{\frac{1-G}{1+G}} \log \left(1-\frac{i-1}{N}\right)-\left(1-\frac{i}{N}\right)^{\frac{1-G}{1+G}} \log \left(1-\frac{i}{N}\right)\right]\right\}
$$

Setting all $\mathrm{N}$ individuals' income ranked from low to high we get:

$$
\frac{\partial Y_{L}}{\partial G}=\frac{-2 Y}{(1+G)^{2}} \sum_{i=1}^{N}\left\{g^{\prime}\left(\mathrm{y}_{\mathrm{i}}\right)\left[\left(1-\frac{i-1}{N}\right)^{\frac{1-G}{1+G}} \log \left(1-\frac{i-1}{N}\right)-\left(1-\frac{i}{N}\right)^{\frac{1-G}{1+G}} \log \left(1-\frac{i}{N}\right)\right]\right\}
$$

Because $g^{\prime \prime}(y)<0, g^{\prime}(y)>0$, we get:

$$
g^{\prime}\left(\mathrm{y}_{1}\right)>g^{\prime}\left(\mathrm{y}_{2}\right)>g^{\prime}\left(\mathrm{y}_{3}\right)>\cdots>g^{\prime}\left(\mathrm{y}_{\mathrm{N}}\right)>0
$$

Expanding the series, we get:

$$
\sum_{i=1}^{N}\left[\left(1-\frac{i-1}{N}\right)^{\frac{1-G}{1+G}} \log \left(1-\frac{i-1}{N}\right)-\left(1-\frac{i}{N}\right)^{\frac{1-G}{1+G}} \log \left(1-\frac{i}{N}\right)\right]=0
$$

Set $u(x)=(1-x)^{a} \log (1-x), \quad 0 \leq x \leq 1,0<a<1$, then:

$$
\mathrm{u}^{\prime}(\mathrm{x})=-\mathrm{a}(1-\mathrm{x})^{\mathrm{a}-1} \log (1-\mathrm{x})+\left(\frac{-1}{1-\mathrm{x}}\right)(1-\mathrm{x})^{\mathrm{a}}=-(1-\mathrm{x})^{\mathrm{a}-1}(\operatorname{aLog}(1-\mathrm{x})+1)
$$

If $\mathrm{x}=1-\mathrm{e}^{-1 / \mathrm{a}}, \mathrm{u}^{\prime}(\mathrm{x})=0$; when $\mathrm{x}<1-\mathrm{e}^{-1 / \mathrm{a}}, \mathrm{u}^{\prime}(\mathrm{x})<0, \mathrm{u}^{\prime}(\mathrm{x})<0$ is a decreasing function; when $\mathrm{x}>1-\mathrm{e}^{-1 / a}, \mathrm{u}^{\prime}(\mathrm{x})>0, \mathrm{u}(\mathrm{x})$ is an increasing function.

Set $i_{0}=\left\lfloor N-N e^{-1 / a}\right\rfloor^{1}$, then $i_{0}<N-N e^{-1 / a}<i_{0}+1$, then $\frac{i_{0}}{N}<1-e^{-1 / a}<\frac{i_{0}+1}{N}$.

When $\mathrm{i} \leq i_{0},\left(1-\frac{i-1}{N}\right)^{\frac{1-G}{1+G}} \log \left(1-\frac{i-1}{N}\right)-\left(1-\frac{i}{N}\right)^{\frac{1-G}{1+G}} \log \left(1-\frac{i}{N}\right)>0$;

\footnotetext{
${ }^{1}$ If the biggest integer is no greater than $\mathrm{x}$.
} 
When $\mathrm{i}>i_{0},\left(1-\frac{i-1}{N}\right)^{\frac{1-G}{1+G}} \log \left(1-\frac{i-1}{N}\right)-\left(1-\frac{i}{N}\right)^{\frac{1-G}{1+G}} \log \left(1-\frac{i}{N}\right)<0$.

Transpose equation (8), we have:

$$
\begin{aligned}
& \sum_{i=1}^{i_{0}}\left[\left(1-\frac{i-1}{N}\right)^{\frac{1-G}{1+G}} \log \left(1-\frac{i-1}{N}\right)-\left(1-\frac{i}{N}\right)^{\frac{1-G}{1+G}} \log \left(1-\frac{i}{N}\right)\right] \\
= & \sum_{i=i_{0}+1}^{N}\left[\left(1-\frac{i}{N}\right)^{\frac{1-G}{1+G}} \log \left(1-\frac{i}{N}\right)-\left(1-\frac{i-1}{N}\right)^{\frac{1-G}{1+G}} \log \left(1-\frac{i-1}{N}\right)\right]
\end{aligned}
$$

Where each item in the series on both sides of equation is greater than 0 , multiply " $g$ ' $\left(\mathrm{y}_{\mathrm{i}}\right)$ " to each item and combined with equation (7), we get:

$$
\begin{aligned}
& \sum_{i=1}^{i_{0}} g^{\prime}\left(\mathrm{y}_{\mathrm{i}}\right)\left[\left(1-\frac{i-1}{N}\right)^{\frac{1-G}{1+G}} \log \left(1-\frac{i-1}{N}\right)-\left(1-\frac{i}{N}\right)^{\frac{1-G}{1+G}} \log \left(1-\frac{i}{N}\right)\right] \\
> & \sum_{i=i_{0}+1}^{N} g^{\prime}\left(\mathrm{y}_{\mathrm{i}}\right)\left[\left(1-\frac{i}{N}\right)^{\frac{1-G}{1+G}} \log \left(1-\frac{i}{N}\right)-\left(1-\frac{i-1}{N}\right)^{\frac{1-G}{1+G}} \log \left(1-\frac{i-1}{N}\right)\right]
\end{aligned}
$$

Transposition: $\sum_{i=1}^{N}\left\{g^{\prime}\left(\mathrm{y}_{\mathrm{i}}\right)\left[\left(1-\frac{i-1}{N}\right)^{\frac{1-G}{1+G}} \log \left(1-\frac{i-1}{N}\right)-\left(1-\frac{i}{N}\right)^{\frac{1-G}{1+G}} \log \left(1-\frac{i}{N}\right)\right]\right\}>0, \quad$ then: $\frac{\partial Y_{L}}{\partial G}=$ $\frac{-2 Y}{(1+G)^{2}} \sum_{i=1}^{N}\left\{g^{\prime}\left(\mathrm{y}_{\mathrm{i}}\right)\left[\left(1-\frac{i-1}{N}\right)^{\frac{1-G}{1+G}} \log \left(1-\frac{i-1}{N}\right)-\left(1-\frac{i}{N}\right)^{\frac{1-G}{1+G}} \log \left(1-\frac{i}{N}\right)\right]\right\}<0$

$$
\partial \mathrm{e} / \partial \mathrm{G}=\frac{1}{Y} \frac{\partial Y_{L}}{\partial G}<0 .^{2}
$$

Proposition 4: When $g^{\prime \prime}(y)<0$, that is to say when the marginal labor income decreases, the national labor income share is the decreasing function of the gross national income, $\partial \mathrm{e} / \partial \mathrm{Y}<0$.

Demonstration: according to equation (6), we have:

$$
\begin{aligned}
\frac{\partial e}{\partial Y}=\frac{1}{Y} \sum_{i=1}^{N} g^{\prime}\left(\mathrm{y}_{\mathrm{i}}\right)\left[\left(1-\frac{i-1}{N}\right)^{\frac{1-G}{1+G}}\right. & \left.-\left(1-\frac{i}{N}\right)^{\frac{1-G}{1+G}}\right]-\frac{1}{Y^{2}} \sum_{i=1}^{N} g\left(Y\left[\left(1-\frac{i-1}{N}\right)^{\frac{1-G}{1+G}}-\left(1-\frac{i}{N}\right)^{\frac{1-G}{1+G}}\right]\right) \\
= & \frac{1}{Y^{2}}\left\{\sum_{i=1}^{N}\left[g^{\prime}\left(y_{i}\right) y_{i}-g\left(y_{i}\right)\right]\right\}
\end{aligned}
$$

Because $g^{\prime \prime}(y)<0$, for any $y_{0} \in(0, y)$ we have: $g^{\prime}\left(y_{0}\right)>g^{\prime}(y)$

According to Lagrange's mean value theorem, there exists a $y_{0} \in(0, y)$, making $\frac{g(y)-g(0)}{y-0}=g^{\prime}\left(y_{0}\right)$,

$g(0)=0$ and then $\frac{g(y)}{y}=g^{\prime}\left(y_{0}\right)$, therefore $g^{\prime}(y)<\frac{g(y)}{y}$, it is: $\frac{g(y)}{y}=g^{\prime}\left(y_{0}\right), y g^{\prime}(y)-g(y)<0$, then:

$\partial e / \partial Y<0$.

c. Calculating Gini coefficient variation's influence on national labor income and its share: difference formula

To the best of our knowledge, the literature of calculating the Gini coefficient's impact on labor income share is very limited. In this section, we use a national labor income function with the Gini coefficient to establish the

${ }^{2}$ It is worth emphasizing that the conditions for the decreasing marginal labor income is the elasticity replacement of capital. labor being greater than 1 . In the process of economic development, the elastic coefficient may change, otherwise according to this proposition labor income proportion may decrease to zero, which intuitively obviously does not conform to reality. 
difference formula, which can calculate the influence exerted by Gini coefficient variations on the national labor income and its share.

According to equation (5), the national income Y, Gini coefficient G, and micro-labor income function $\omega=g(\mathrm{y})$, are all influencing factors. Because excepting income $\mathrm{Y}$, there are many other factors which influence the labor income function. These factors may be changeable, so if we assume $z$ is other factors, then income function can be rewrite as $\omega=g(\mathrm{y}, \mathrm{z})$. Taking difference to equation (5), we have

$$
\begin{gathered}
\Delta Y_{L}=\sum_{i=1}^{N} g_{z}^{\prime}\left(\mathrm{y}_{\mathrm{i}}, \mathrm{z}\right) \Delta z+\frac{1}{Y} \sum_{i=1}^{N}\left[g_{y}^{\prime}\left(\mathrm{y}_{\mathrm{i}}, \mathrm{z}\right) \mathrm{y}_{\mathrm{i}}\right] \Delta Y \\
-\frac{2 Y}{(1+G)^{2}} \sum_{i=1}^{N}\left\{g_{y}^{\prime}\left(\mathrm{y}_{\mathrm{i}}, \mathrm{z}\right)\left[\left(1-\frac{i-1}{N}\right)^{\frac{1-G}{1+G}} \log \left(1-\frac{i-1}{N}\right)-\left(1-\frac{i}{N}\right)^{\frac{1-G}{1+G}} \log \left(1-\frac{i}{N}\right)\right]\right\} \Delta G \\
\text { Where } \mathrm{y}_{\mathrm{i}}=Y\left[\left(1-\frac{i-1}{N}\right)^{\frac{1-G}{1+G}}-\left(1-\frac{i}{N}\right)^{\frac{1-G}{1+G}}\right]
\end{gathered}
$$

The first item on the right is the influence exerted by 'other factors change' on the gross labor income (set as $A_{g} \Delta g$ ); the second item is the influence that the gross national income change exerts on labor income (set as $\mathrm{A}_{G} \Delta G$ ). The third item is the influence that the Gini coefficient variation exert on labor income (set as $\mathrm{A}_{G} \Delta$ ). Each item divides $\Delta Y_{L}$ we can get the relative contribution rate of each factor to gross labor income change.

Taking difference to equation. (6), we have

$$
\begin{array}{r}
\Delta \mathrm{e}=\frac{1}{Y} \sum_{i=1}^{N} g_{z}^{\prime}\left(\mathrm{y}_{\mathrm{i}}, \mathrm{z}\right) \Delta z+\frac{1}{Y^{2}}\left\{\sum_{i=1}^{N} g_{y}^{\prime}\left(\mathrm{y}_{\mathrm{i}}, \mathrm{z}\right) \mathrm{y}_{\mathrm{i}}-\sum_{i=1}^{N} g\left(\mathrm{y}_{\mathrm{i}}, \mathrm{z}\right)\right\} \Delta Y \\
-\frac{2}{(1+G)^{2}} \sum_{i=1}^{N}\left\{g_{y}^{\prime}\left(\mathrm{y}_{\mathrm{i}}, \mathrm{z}\right)\left[\left(1-\frac{i-1}{N}\right)^{\frac{1-G}{1+G}} \log \left(1-\frac{i-1}{N}\right)-\left(1-\frac{i}{N}\right)^{\frac{1-G}{1+G}} \log \left(1-\frac{i}{N}\right)\right]\right\} \Delta G
\end{array}
$$

The first item on the right is other factors' change effects on the gross labor income share (set as $B_{g} \Delta g$ ). The second item is the influence that the gross national income change exerts on labor income proportion (set as $B_{Y} \Delta Y$ ). The third item is the influence that the Gini coefficient variation exerts on labor income proportion (set as $B_{G} \Delta G$ ). Each item divides $\Delta \mathrm{e}$ then we can see the relative contribution rate of each relative factor to gross labor income share change.

If we take difference to variables, we actually assumed the change of variable is slight. In the deduction process, items higher than the second order derivative such as $\Delta Y \Delta G$ can be ignored. Therefore, we need to make sure that the variable rate is relatively small in practice.

\section{Empirical Analysis}

a. elasticity of capital-labor substitution and the estimation of labor income function's parameter

According to equation (1), the labor income function is $\omega=b y^{1 / \sigma}$. The elasticity of capital-labor substitution and the parameter $\mathrm{b}$ can be estimated by using this function. We consider the situation that $\mathrm{b}$ changes over time while the $\sigma$ is constant. That is $\omega_{t}=b_{t} y_{t}^{1 / \sigma}$. Taking the logarithm to both sides, we get: $\operatorname{Ln}\left(\omega_{t}\right)=\operatorname{Ln}\left(b_{t}\right)+$ $(1 / \sigma) \operatorname{Ln}\left(y_{t}\right)$, so we can set the panel regression model:

$$
\text { LNPERINCL } L_{i t}=a_{0}+\beta_{t}+a_{1} L N P E R G D P_{i t}+\varepsilon_{i t}
$$

Where $i$ refers to province, $\mathrm{t}$ refers to year, LNPERINCL $\mathrm{L}_{\mathrm{it}}$ refers to log value of per capita income for worker, LNPERGDP ${ }_{\text {it }}$ refers to value of per capita GDP, $\beta_{\mathrm{t}}$ refers to period fixed effects, $\varepsilon_{i t}$ refers to the random item, $a_{0}+\beta_{t}$ refers to the estimation of $\operatorname{Ln}\left(b_{t}\right), a_{1}$ refers to the estimation of $1 / \sigma$; we then easily get: $b_{t}=e^{a_{0}+\beta_{t}}$, $\sigma=1 / a_{1}{ }^{3}$

Provincial panel data from 1996 to 2010 are used for estimation. All nominal variables are adjusted by applying deflator (1996 is the basis year). All data are from the annual China Statistical Yearbook. EVIEWS6.0 software

\footnotetext{
${ }^{3}$ In order to analyze the relationship between workers' remuneration and gross national income, the income index of GDP per capita data uses both the income method and also gross national income. Because the caliber is unified, the theoretical propositions are applicable for these data. The national income Y of the theoretical model is set to GDP of the income method. It will not be explained later.
} 
was used to simulate the data; $F$ test supports variable intercept model, and Hausman test supports fixed effects model. We use the generalized least squares method (EGLS) to deal with heteroskedasticity of the fixed effects model and sequence correlation. Results are shown in Table 1.

Table 1. Estimation and test results

\begin{tabular}{ccccccc}
\hline Variable & Coefficient & 1996 & 1997 & 1998 & 1999 & 2000 \\
\hline CONS & $0.828332 * * *(9.3639)$ & 0.006057 & 0.009243 & 0.027402 & 0.027786 & 0.016322 \\
LNPERGDP & $0.832925^{* * *}(87.1857)$ & 2001 & 2002 & 2003 & 2004 & 2005 \\
Regulated R & 0.9691 & 0.032815 & 0.035404 & 0.027484 & -0.04292 & -0.10044 \\
F statistics (P value) & $938.6485^{* * *}(0.0000)$ & 2006 & 2007 & 2008 & 2009 & 2010 \\
observations & 449 & -0.10425 & -0.11943 & 0.014841 & 0.089435 & 0.080452 \\
\hline
\end{tabular}

From Table 1, we see that F-statistics is significant at the $1 \%$ level, and the constant term as well as the variation coefficient are also significant at the $1 \%$ level. Adjusted $\mathrm{R}^{2}$ is 0.9691 , therefore the regression has high degree of fitting. We can easily get $\sigma=1 / a_{1}=1.200588$. The results of $b_{t}=e^{a_{0}+\beta_{t}}$ is shown in Table 1 . We can see that the constant elasticity of capital-labor substitution $\sigma>1$, therefore according to proposition 1, marginal labor income is decreasing. Further, According to proposition 3, we can see that the increase of Gini coefficient will decrease the national gross labor income and its share (and vice versa). Meanwhile according to proposition 4 , we can predict that the national labor income share is a decreasing function of gross national income.

b. quantitative analysis of Gini coefficient effects on labor-share in GDP: regression method

In order to test the above-mentioned results, according to propositions 3 and 4, we use Gini coefficient, GDP and the provincial panel data of workers' income-share (1996-2010). Set the regression model as,

$$
E_{i t}=b_{0}+b_{1} G I N I_{i t}+b_{2} \text { PERGDP } i t+u_{i}+\varepsilon_{i t}
$$

Where $i$ refers to province, $t$ refers to year, $\mathrm{E}_{\mathrm{it}}$ refers to the proportion of workers' remuneration in GDP, $\mathrm{GINI}_{\mathrm{it}}$ refers to Gini coefficient, PERGDP ${ }_{\text {it }}$ refers to per capita GDP (income approach) ${ }^{4}, \mathrm{u}_{\mathrm{i}}$ refers to intercept effects, $\varepsilon_{\text {it }}$ refers to a random error term. The Gini coefficient is calculated by the provincial income grouped data ${ }^{5}$, the proportion of the remuneration for workers in GDP per capita is calculated by statistical data ${ }^{6}$, the data resource is the same as above-mentioned. F test supports the variable intercept model, and Hausman test supports the fixed effects model. Then we use the generalized least squares method (EGLS) to deal with heteroskedasticity of the fixed effects model and sequence correlation, the result is as follows:

$$
\begin{aligned}
E_{i t}= & 0.7294-0.5114 G_{1 N I_{i t}}-3.05 \times 10^{-6} P E R G D P_{i t} \\
& \left(37.50036^{* * *}\right)\left(-9.136724^{* * *}\right) \quad\left(-8.810415^{* * *}\right)
\end{aligned}
$$

"t" in brackets is test value, ${ }^{* * *}$ shows $1 \%$ significance level. F statistics is 27.024 , probability p value is 0.0000 , adjusted $R^{2}$ is 0.67363 , sample observation is 392 .

We can see that the regression coefficient of Gini coefficient is negative, which means the increase of the Gini coefficient will decrease the share of labor income. The per capita GDP is also negative, which means the increase of national income will decrease the share of labor income. Thus, propositions 3 and 4 are correct and the results above are reliable.

c. quantitative analysis of Gini coefficient effects on labor's share of GDP: method of difference

Both changes in the Gini coefficient and changes in the national income will affect the labor income-share. What is the exact influence in China? According to the ratio of labor income and its share in GDP from 1996 to 2010, we can calculate the effects of change. Using the above-estimated labor income function as the micro-labor income function, we can calculate each parameter as shown in Table 2.

\footnotetext{
${ }^{4}$ According to theoretical derivation, income shall be the gross national income. However, if we use the provincial panel data, the impact of population difference on gross income is very big, so we instead use per capita GDP to eliminate the influence of population difference.

5 The Gini coefficient is calculated by using grouping resident income.

${ }^{6}$ Labor income in the GDP data uses the revenue method. Because there is the only provincial statistical yearbook data, this paper aggregates the provincial data.
} 
Table 2. Year 1996-2010 variables

\begin{tabular}{lllllllll}
\hline & $\begin{array}{l}\text { GDP } \\
\text { C¥100 } \\
\text { million }\end{array}$ & $\begin{array}{l}\text { Labor } \\
\text { income } \\
\text { C¥100 } \\
\text { million }\end{array}$ & $\begin{array}{l}\text { labor } \\
\text { share }\end{array}$ & $\begin{array}{l}\text { Urban } \\
\text { gini Gc }\end{array}$ & $\begin{array}{l}\text { Rural } \\
\text { gini Gr }\end{array}$ & $\begin{array}{l}\text { Residents } \\
\text { gini G }\end{array}$ & $\begin{array}{l}\text { Parameter } \\
\text { b }\end{array}$ & $\begin{array}{l}\text { Population } \\
\text { N }\end{array}$ \\
& & & & & & \\
'000
\end{tabular}

Note: GDP and labor income are both regulated based on Calm base price index in 1996

Where $\mathrm{b}$ is a parameter in above-estimated micro-labor income function. GDP is the gross national income. The remuneration for workers YL and the population N are from China Statistical Year book in every year. The labor share $\mathrm{e}$ is the proportion of remuneration for workers in $\mathrm{GDP}^{7}$; Gini coefficient $(\mathrm{G})$ is calculated by using urban Gini coefficient (Gc) and rural Gini coefficient (Gr) with weighting method (Chen, 2002; Zhou, 2009) ${ }^{8}$. The data of $\mathrm{Gc}$ and $\mathrm{Gr}$ are from the NBS.

According to equations (9) and (10), we use $\mathrm{C}++$ writer and Visual $\mathrm{C}++6.0$ compiling software to calculate the absolute contribution and relative contribution of the effects that each factor variation exerts on the national labor income and its share, as shown in Table 3 and Table 4. The main calculation error is illustrated in Table 5.

Table 3. Influence of various factors on the national labor income changes

\begin{tabular}{llllllll}
\hline & $\begin{array}{c}A_{g} \Delta g \\
\mathbf{C} \mathbf{1 0 0} \\
\text { million }\end{array}$ & $\begin{array}{c}A_{Y} \Delta Y \\
\mathbf{C} \mathbf{1 0 0} \\
\text { million }\end{array}$ & $\begin{array}{l}A_{G} \Delta G \\
\mathbf{C} \mathbf{1 0 0} \\
\text { million }\end{array}$ & $\begin{array}{l}\Delta Y L \\
\text { Total } \\
\mathbf{C} \mathbf{1 0 0} \\
\text { million }\end{array}$ & $\begin{array}{l}A_{g} \Delta g / \\
\Delta Y L \text { (\%) }\end{array}$ & $\begin{array}{l}A_{Y} \Delta Y / \\
\Delta Y L \text { (\%) }\end{array}$ & $\begin{array}{l}A_{G} \Delta G / \\
\Delta Y L \text { (\%) }\end{array}$ \\
$1996-1997$ & 106.2 & 2423.2 & -2.8 & -2.8 & 4.20 & 95.91 & -0.11 \\
$1997-1998$ & 731.3 & 2530.2 & -111.5 & -111.5 & 23.22 & 80.32 & -3.54 \\
$1998-1999$ & 16.3 & 2747.8 & -214.6 & -214.6 & 0.64 & 107.78 & -8.42 \\
$1999-2000$ & -514.5 & 3832.8 & -334.6 & -334.6 & -17.24 & 128.46 & -11.21 \\
\hline
\end{tabular}

\footnotetext{
7 The date of workers' compensation and labor's share shown here is to compare with the calculated value of the theoretical model and judge the accuracy of the models.

${ }^{8}$ The calculated formula is: $G=p_{c}^{2}\left(u_{c} / u\right) G_{c}+p_{r}^{2}\left(u_{r} / u\right) G_{r}+p_{c} p_{r}\left|u_{c}-u_{r}\right| / u$. Where $G, G_{c}, G_{r}$ is gross, urban and rural Gini coefficient; $p_{c}, p_{r}$ is the proportion of urban and rural population, $u_{c}, u_{r}$ is the per capita income in urban and rural areas; and $u$ is the per capita income of residents. This method was proposed by Sundrum (1990).
} 


\begin{tabular}{llllllll}
\hline $2000-2001$ & 800.4 & 3910.4 & -267.2 & -267.2 & 18.01 & 88.00 & -6.01 \\
$2001-2002$ & 136.6 & 4661.6 & -756.7 & -756.7 & 3.38 & 115.34 & -18.72 \\
$2002-2003$ & -448.0 & 5455.6 & -348.7 & -348.7 & -9.62 & 117.10 & -7.48 \\
$2003-2004$ & -4176.8 & 6802.5 & -41.7 & -41.7 & -161.64 & 263.26 & -1.61 \\
$2004-2005$ & -3553.3 & 6867.6 & -130.1 & -130.1 & -111.59 & 215.68 & -4.09 \\
$2005-2006$ & -252.0 & 8795.2 & -69.0 & -69.0 & -2.97 & 103.79 & -0.81 \\
$2006-2007$ & -1126.9 & 13442.8 & -43.5 & -43.5 & -9.18 & 109.54 & -0.35 \\
$2007-2008$ & 12459.8 & 6809.8 & -136.8 & -136.8 & 65.12 & 35.59 & -0.72 \\
$2008-2009$ & 8274.6 & 13504.2 & 31.6 & 31.6 & 37.94 & 61.92 & 0.14 \\
$2009-2010$ & -1159.3 & 17077.0 & 764.8 & 764.8 & -6.95 & 102.36 & 4.58 \\
$1996-2008$ calculated & 4179.1 & 68279.5 & -2457.1 & 70001.57 & 5.97 & 97.54 & -3.51 \\
$2008-2010$ calculated & 7115.4 & 30581.2 & 796.3 & 38492.94 & 18.48 & 79.45 & 2.07 \\
$1996-2010$ calculated & 11294.5 & 98860.7 & -1660.7 & 108494.5 & 10.41 & 91.12 & -1.53 \\
\hline
\end{tabular}

Table 4. The impact of various factors change to the national labor income share

\begin{tabular}{cccccccc}
\hline & $B_{g} \Delta g$ & $B_{Y} \Delta Y$ & $B_{G} \Delta G$ & Total & $B_{g} \Delta g /$ & $B_{Y} \Delta Y /$ & $B_{G} \Delta G /$ \\
& & & & $\Delta e$ & $\Delta e(\%)$ & $\Delta e(\%)$ & $\Delta e(\%)$ \\
\hline $1996-1997$ & 0.00090 & -0.00410 & -0.00002 & -0.00323 & -27.76 & 127.04 & 0.72 \\
$1997-1998$ & 0.00571 & -0.00396 & -0.00087 & 0.00088 & 650.97 & -451.76 & -99.20 \\
$1998-1999$ & 0.00012 & -0.00400 & -0.00156 & -0.00543 & -2.18 & 73.54 & 28.63 \\
$1999-2000$ & -0.00346 & -0.00517 & -0.00225 & -0.01088 & 31.80 & 47.52 & 20.68 \\
$2000-2001$ & 0.00489 & -0.00479 & -0.00163 & -0.00153 & -318.65 & 312.27 & 106.38 \\
$2001-2002$ & 0.00076 & -0.00520 & -0.00421 & -0.00865 & -8.78 & 60.13 & 48.66 \\
$2002-2003$ & -0.00225 & -0.00550 & -0.00175 & -0.00951 & 23.69 & 57.87 & 18.44 \\
$2003-2004$ & -0.01883 & -0.00615 & -0.00019 & -0.02517 & 74.81 & 24.44 & 0.75 \\
$2004-2005$ & -0.01414 & -0.00548 & -0.00052 & -0.02014 & 70.21 & 27.22 & 2.57 \\
$2005-2006$ & -0.00089 & -0.00621 & -0.00024 & -0.00735 & 12.09 & 84.61 & 3.31 \\
$2006-2007$ & -0.00342 & -0.00819 & -0.00013 & -0.01175 & 29.14 & 69.73 & 1.13 \\
$2007-2008$ & 0.03114 & -0.00341 & -0.00034 & 0.02739 & 113.72 & -12.47 & -1.25 \\
2008-2009 & 0.05670 & -0.01856 & 0.00022 & 0.03836 & 147.83 & -48.39 & 0.56 \\
2009-2010 & -0.00690 & -0.02038 & 0.00455 & -0.02273 & 30.35 & 89.67 & -20.02 \\
$1996-2008$ calculated & 0.00052 & -0.06218 & -0.01372 & -0.07538 & -0.69 & 82.49 & 18.20 \\
2008-2010 calculated & 0.04980 & -0.03894 & 0.00477 & 0.01563 & 318.67 & -249.17 & 30.50 \\
$1996-2010$ calculated & 0.05032 & -0.10112 & -0.00895 & -0.05975 & -84.23 & 169.25 & 14.98 \\
\hline
\end{tabular}

According to the calculation error in Table 5, the relative error in different periods between the calculated value statistics of the labor income and its share is around $10 \%$. Generally speaking, the model is accurate. The error is mainly from the labor income function estimation error'; besides, the Gini coefficient calculation may also have some error element.

\footnotetext{
${ }^{9}$ As the data in this paper uses a time-fixed effects model based on provincial panel data to estimate the change of the intercept, so there is a certain element of error. The most viable option would be to use annual micro-data for the calculation.
} 
From Table 3 and Table 4, we can see that the Gini coefficient changes exert effect on the national labor income and the share negatively. That means the Gini coefficient increase (decrease) will cause the decrease (increase) in the gross national labor income and its share. ${ }^{10}$ This result is in agreement with our theoretical propositions. From 1996-2010, the Gini coefficient of residents in China increased from 0.3688 to 0.4613 , which caused a decline in national labor income by C¥166.07 billion (1996 constant, similarly hereinafter) and the national labor income share dropped by $0.895 \%$. The contribution rates of Gini coefficient changes to the national labor income and its share is $-1.53 \%$ and $14.98 \%$ respectively. ${ }^{11}$

Table 5. Calculated value and the absolute error and relative error of statistics

\begin{tabular}{|c|c|c|c|c|c|c|c|c|}
\hline & $\begin{array}{l}\text { Labor } \\
\text { income } \\
\text { change - } \\
\text { statistics } \\
\text { C¥100 } \\
\text { million }\end{array}$ & $\begin{array}{c}\text { Labor income } \\
\text { change - } \\
\text { calculated } \\
\text { C¥100 million }\end{array}$ & $\begin{array}{l}\text { Absolute } \\
\text { error } \\
\text { C¥100 } \\
\text { million }\end{array}$ & $\begin{array}{c}\text { Relative } \\
\text { error } \\
\%\end{array}$ & $\begin{array}{l}\text { Labor share } \\
\text { of GDP } \\
\text { change - } \\
\text { statistics }\end{array}$ & $\begin{array}{l}\text { Labor share } \\
\text { of GDP } \\
\text { change - } \\
\text { calculated }\end{array}$ & $\begin{array}{c}\text { Absolute } \\
\text { error }\end{array}$ & $\begin{array}{c}\text { Relative } \\
\text { error }\end{array}$ \\
\hline $1996-2008$ & 76881.1 & 70001.6 & -6879.5 & -8.95 & -0.0824 & -0.0754 & 0.0070 & -7.25 \\
\hline $2008-2010$ & 44207.6 & 38492.9 & -5714.7 & -12.93 & 0.0180 & 0.0156 & -0.0024 & -8.55 \\
\hline $1996-2010$ & 121088.7 & 108494.5 & -12594.2 & -10.40 & -0.0644 & -0.0597 & 0.0047 & -13.19 \\
\hline
\end{tabular}

Looking from the different periods, in 1996-2008, the Gini coefficient in China gradually increased from 0.3688 to 0.4613 . During this period, the Gini coefficient change resulted in the decrease of national labor income by C $¥ 245.71$ billion and the labor share fell $1.372 \%$. Its contributions to the national labor income proportion changes were $-3.51 \%$ and $18.20 \%$ respectively. The Gini coefficient decreased from 0.4718 to 0.4613 in the period of 2008 to 2010. During this time, the Gini coefficient changes led national income to increase by C $¥ 79.63$ billion and labor share to increase by $0.47 \%$. The relative contribution rates are $2.07 \%$ and $30.5 \%$ respectively.

The effect that the Gini coefficient imposed on the national labor income share is shown in Figure 2. The Gini coefficient shows the inverted U-shaped characteristic and the real labor proportion shows the U-shaped characteristic (the two vertices appear in 2007/2008). Note that this influence is negative. If we only consider the factor of the Gini coefficient change, the labor income share would show the U-shaped characteristic. ${ }^{12}$ This means that the Gini coefficient change is also a significant influence factor for labor share's U-shape characteristic.

\footnotetext{
10 This is simply the influence of the Gini coefficient. The change of national labor income and the proportion should also consider other factors.

${ }_{11}$ The contribution rate for each factor is defined above, the two relative contribution sizes are different, so they are not comparable.

${ }_{12}$ The actual labor share in 1996 is used as a benchmark. The labor share trend assumes annual changes after 1996 are affected by the Gini coefficient change (other factors being fixed).
} 

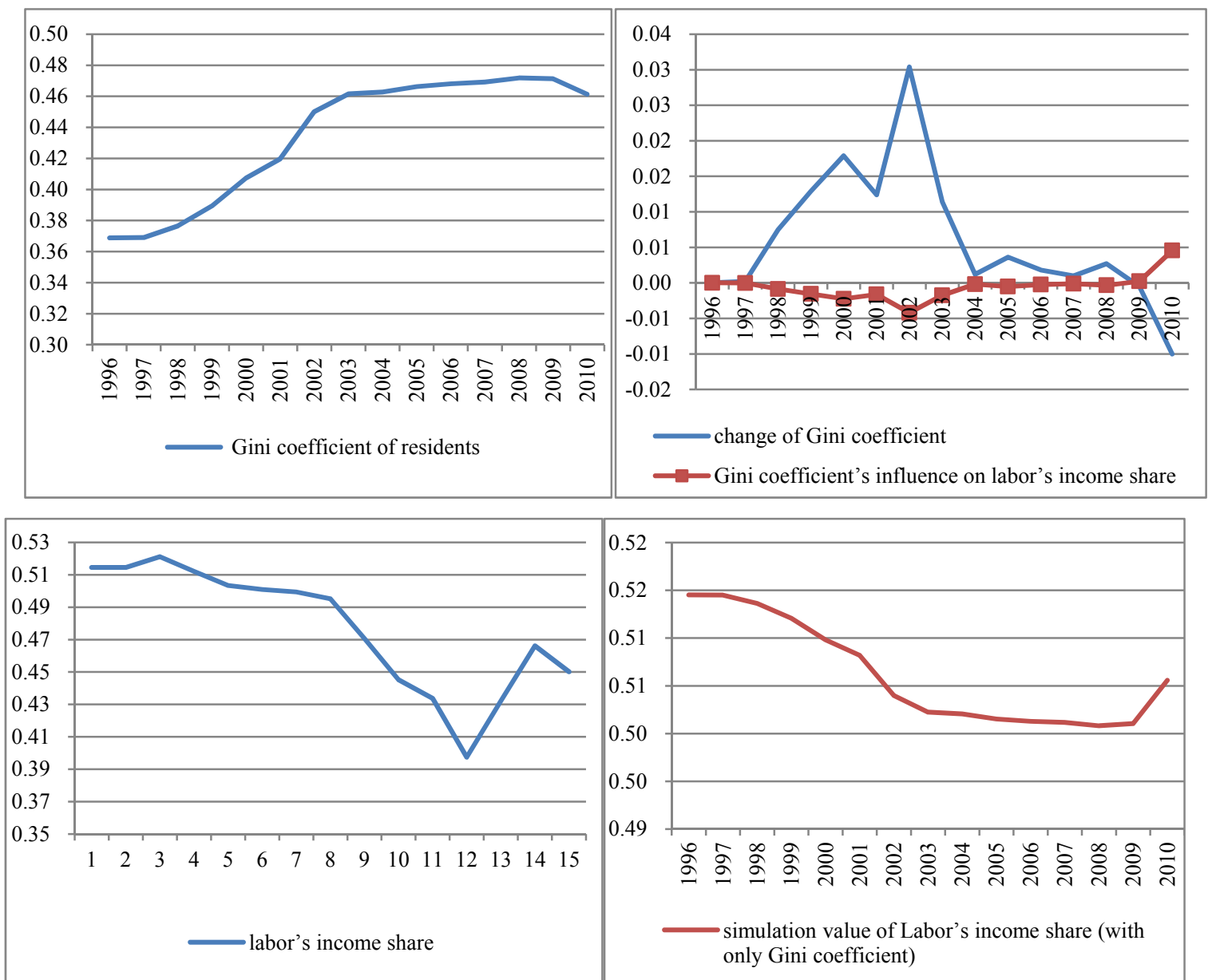

Figure 2. The gini coefficient and the change of the labor share

\section{Conclusion}

This paper assesses the labor income share in China from the perspective of income differences through both theory and practice. The main work consists of three aspects.

First, we deduced the condition of individual marginal labor income decreasing through a neoclassical production model and constant elasticity of substitution production function. The condition is that the elasticity of capital-labor substitution is greater than 1 . By estimating actual elasticity of capital-labor substitution in China based on provincial panel data from 1996 to 2010, we confirm that this substitution elasticity is greater than 1, which means that marginal labor income for workers in China is decreasing.

Second, by using the Lorenz curve function of income distribution based on the classical Pareto income distribution, we established a national gross labor income function incorporating the Gini coefficient. We find that the decreasing marginal labor income is explained by the incorporation of the Gini coefficient decrease national gross labor income and its proportion. It shows that the increase of the Gini coefficient is a significant factor in the national labor income and the decline of labor's share in China.

Third, by using the national gross labor income function, we built a metering method to calculate the effect that Gini coefficient variation exerts on national gross labor income and its share. Then we utilized this method to disaggregate labor income and its share in China annually. The results show that the $15 \%$ decline of national labor income share from 1996 to 2010 is explained by the addition of the Gini coefficient. The Gini coefficient increase from 1996-2008 led to a labor share increase of 1.37\%. The Gini coefficient decline from 2008-2010 led to a labor share increase of $0.47 \%$. The Gini coefficient 'inverted U' type characteristics can partly explain U-shaped characteristics in the evolution of labor's share of GDP.

We proposed a new perspective for studying China's labor income-share, which can help expand the theoretical horizon. Also, the national labor income function with Gini coefficient and the approaches for measuring the 
influence exerted by the Gini coefficient on national labor income share are innovative. These theoretical and empirical innovations are valuable for further research in this field. In application, we showed that income difference changes can help explain changes in labor's income-share.

At present, China's labor income and its share could increase if

- capital markets were improved

- household registration system (hukou) were reformed

- regional protectionism and the urban-rural divide were broken

- national marketisation levels were improved

- production factors flowed more freely

- the wealth gap were to shrink

Considering the Gini coefficient in calculations of China's labor income-share could contribute to more equitable marketization and perfection of economic systems and mechanisms in China.

\section{Acknowledgements}

Funding for this project was provided by Guangdong Province Science and technology Planning Project (2015A070704057) \& National Fund Development of Shantou University (NFC16003).

\section{References}

Askenazy, P. (2005). Trade, Services and Wage Inequality. Oxford Economic Paper, 57(4), 674-692. https://doi.org/10.1093/oep/gpi026

Bai, C. E., \& Qian, Z. J. (2009). Factor Income Share in China: The Story behind the Statistics. Economic Research Journal, 3.

Bai, C. E., \& Qian, Z. J. (2009). Who Has Eroded Residents' Incomes? An Analysis of China's National Income Distribution Patterns. Social Sciences in China, 5.

Bai, C. E., \& Qian, Z. J. (2010). Determinants of Labor Income Share: Evidence from Provincial Panel Data in China. Journal of World Economy, 12, 7.

Beach, C., \& Davidson, R. (1983). Distribution-free Statistical Inference with Lorenz Curves and Income Shares. Review of Economic Studies, 50(4), 723-735. https://doi.org/10.2307/2297772

Bentolila, S., \& Saint-Paul, G. (2003). Explaining Movements in the Labor Share. Contributions to Macroeconomics, 3(1), article 9. https://doi.org/10.2202/1534-6005.1103

Daudey, E., \& Garcia-Penalosa, C. (2007). Personal and Factor Distributions of Income in a Cross-section of Countries. Journal of Development Studies, 43(5), 812-829. https://doi.org/10.1080/00220380701384406

David, D. K., Lia, L., Lin, L. N., \& Wang, H. L. (2009). The U Curve of Labor Share in GDP During Economic Development. Economic Research Journal, 1.

Fang, W. Q. (2011). Empirical Study of China's Labor Income Share Determinants: Restructuring or Financial Effects? Journal of Financial Research, 2.

Gong, G., \& Yang, G. (2010). On the Evolution of the Wage Share in National Income. Management World, 5.

Huang, X.H., \& Xu, S. (2009). Reasons for the Decline of Labor Share: From the Angle of Labor-saving Technical Progress. Economic Research Journal, 7.

Jayadev, A. (2007). Capital Account Openness and the Labor Share of Income. Cambridge Journal of Economics, 31(3), pp. 423-443. https://doi.org/10.1093/cje/bel037

Kabaca, S. (2011). Labor Share Fluctuations in Emerging Markets: The Role of the Cost of Borrowing, University of British Columbia, working paper, Sep. 2011.

Kaldor, N. (1961). Capital Accumulation and Economic Growth. In F. A. Lutz \& D. C. Hague (Eds.), The Theory of Capital (pp. 177-222). St. Martins Press. https://doi.org/10.1007/978-1-349-08452-4_10

Li, D. K., He, M. J., \& Liu, L. L. (2010). The Dynamic Labor Share in Primary Distribution. Economic Theory and Business Management, 2.

Luo, C. Y., \& Chen, L. (2012). Do Financing Constraints Lead to Decline of the Labor Share. Journal of Financial Research, 3. 
Luo, C. Y., \& Zhang, J. (2009). Labor Income Share and Economic Development: An Empirical Study Based on Chinese Industry-level Data. Social Sciences in China, 4.

Luo, C. Y., \& Zhang, J. (2009). The Economic Explanation of Labor income share decline. Management World, 5 .

Min, S., \& Huang, J. L. (2010). Foreign Investment and the Labor Share in China: An Empirical Study Based on Industrial Level Panel Data. China Economic Quarterly, 4.

Sarabia, J. M., Castillo, E., \& Slottje, D. J. (1999). An Ordered Family of Lorenz Curves. Journal of Econometrics, 91(1), 43-60. https://doi.org/10.1016/S0304-4076(98)00048-7

Shi, L., \& Ma, S. G. (2006). The Formation Mechanism of Market Segmentation and Institutional Arrangement to Unify China's Markets. Journal of Renmin University of China, 3.

Sundrum, R. M. (1990). Income Distribution in Less Developed Countries. London and New York: Routledge. https://doi.org/10.4324/9780203168493

Wang, S. T., \& Wu, C. L. (2012) Impact of Income Distribution on Aggregate Consumption of Chinese Residents: Theoretical and Empirical Analysis of Marginal Propensity to Consume. Economic Review, 6.

Wang, S. T., Yang, W., \& Wu, C. L. (2011). Construction and Estimates of Gross National Utility Function in China. Statistical Research, 4.

Wei, X. H., Dong, Z. Q., \& Zhao, Q. Y. (2012). Changes in Population Age Structure and Labor Income Share: Theory and Research. Nankai Economic Studies, 2.

\section{Copyrights}

Copyright for this article is retained by the author(s), with first publication rights granted to the journal.

This is an open-access article distributed under the terms and conditions of the Creative Commons Attribution license (http://creativecommons.org/licenses/by/4.0/). 